\title{
IMPACTOS DO ATERRO SANITÁRIO DO MUNICÍPIO DE TRÊS CORAÇÕES, MINAS GERAIS, NA QUALIDADE DA ÁGUA SUBTERRÂNEA
}

\author{
Millena Mirella Vieira TAVEIRA ${ }^{1}$ \\ Antônio Marciano da SILVA² \\ Luciano dos Santos RODRIGUES 3
}

\begin{abstract}
${ }^{1}$ Millena Mirella Vieira Taveira, Engenheira Agrícola, Mestre em Recursos Hídricos em Sistemas Agrícolas. millenataveira@yahoo.com.br.

${ }^{2}$ Antônio Marciano da Silva, Professor Visitante Sênior Nacional na Universidade Federal de Alfenas, Doutor em Engenharia Hidráulica e Saneamento. marciano@deg.ufla.br.

${ }^{3}$ Luciano dos Santos Rodrigues, Professor Adjunto da Universidade Federal de Minas Gerais, Pós-Doutorado em Controle Ambiental e Saneamento. 1santosrodrigues@gmail.com.
\end{abstract}

\section{Recebido em: 19/05/2016 - Aprovado em: 28/07/2016 - Disponibilizado em: 30/07/2016}

\begin{abstract}
RESUMO: A pesquisa teve como principal objetivo avaliar o impacto sobre a qualidade da água subterrânea nas proximidades do aterro sanitário do município de Três Corações, Minas Gerais, por meio de análises físico-químicas e bacteriológicas. Os resultados foram comparados com valores de referência preconizados pela portaria ${ }^{\circ} 2914 / 2011$ do Ministério da Saúde, a Resolução CONAMA n³96/2008 e n420/2009. O impacto do aterro na qualidade da água foi monitorado de janeiro a novembro de 2011 por meio de coleta de água subterrânea em quatro poços de monitoramento. Os resultados mostraram fortes indícios de contaminação pelo chorume devido às alterações de algumas características da água subterrânea, não sendo possível afirmar que este fato esteja sendo ocasionado apenas devido ao aterro, uma vez que o poço a montante também apresentou alterações.
\end{abstract}

Palavras-chave: qualidade; água subterrânea; aterro sanitário; chorume; impacto.

\section{IMPACTS OF THE LANDFILL OF TRÊS CORAÇÕES CITY, MINAS GERAIS, IN GROUNDWATER QUALITY}

\begin{abstract}
This study aimed to assess the impacts on the quality of groundwater near the landfill the town of Três Corações, Minas Gerais, by means analysis of physical, chemical and bacteriological. The results were compared with reference values recommended by the decree $n^{\circ} 2914 / 2011$ of the Ministry of Health, CONAMA Resolution $n^{\circ} 396 / 2008$ and $n^{\circ} 420 / 2009$. The impact of the landfill of Três Corações in the water was monitored from January to November of 2011 through collection in four groundwater wells. The results showed strong evidence of contamination by manure due to changes of some characteristics of the groundwater. It was not possible to say that this fact is being caused only due to the landfill because the upstream wells also showed changes.
\end{abstract}

Key words: quality; groundwater; landfill; manure; impact.

\section{INTRODUÇÃO}

A produção de resíduos sólidos urbanos (RSU) tem aumentado de forma considerável principalmente devido ao aumento populacional, crescimento industrial e incremento na produção de bens e serviços. Geralmente o solo tem sido utilizado como forma de disposição final desses RSU.
Entretanto, na maior parte das cidades brasileiras a disposição final desses resíduos ainda não é feita de forma adequada, o que compromete a qualidade ambiental. Segundo a Pesquisa Nacional de Saneamento Básico o quadro está mudando nos últimos anos, principalmente nas regiões Sul e Sudeste do país. Em 50,8\% dos municípios brasileiros a destinação final dos resíduos são os 
vazadouros a céu aberto, ou seja, os lixões (IBGE, 2008).

A disposição inadequada dos RSU compromete a qualidade da água subterrânea, podendo ser fonte de contaminação devido ao efluente gerado da deterioração do material disposto no solo, o chorume. Este líquido apresenta uma alta carga poluidora podendo conter muitos contaminantes inorgânicos e orgânicos. A qualidade que a água deve apresentar para ser considerada adequada em determinada atividade é definido por padrões de qualidade de diversos parâmetros físicoquímicos e biológicos descritos em legislação ambiental e da saúde (TUCCI \& MENDES, 2006). De acordo com Cotrim (2008), os padrões de qualidade de água são utilizados para regulamentar os níveis de qualidade a serem mantidos em um corpo de água, dependendo do uso a que ele está destinado. São valores de referência de qualidade que servem de instrumento para dar suporte a ações de controle e prevenção das águas subterrâneas. Alguns instrumentos legais são utilizados para avaliar a qualidade das águas.

As águas subterrâneas são menos vulneráveis à contaminação do que as águas superficiais. Mas, uma vez afetadas demandam elevado dispêndio para a sua remediação, o que de modo geral só é alcançado ao final de um longo período e muitas vezes sem a certeza da eficácia dos procedimentos adotados. Em face disso percebe-se a importância do monitoramento da qualidade dessas águas, não somente como uma forma de preservação ambiental, mas também como um monitoramento preventivo para se ter o controle do risco de contaminação. Neste contexto, objetivou-se monitorar e avaliar a qualidade da água subterrânea em uma área sob influência direta de um aterro sanitário, por associação com as substâncias encontradas nesta área, que possam indicar possível contaminação pelo chorume.

\section{MATERIAL E MÉTODOS}

O aterro sanitário em estudo está localizado no município de Três Corações, região sul do estado de Minas Gerais, Brasil, e possui uma população de 72.765 habitantes (IBGE, 2010). O município é banhado pelo Rio Verde, do Peixe, Palmela e Lambari, além de vários ribeirões e córregos, como dois que atravessam o aterro sanitário. De acordo com a classificação Koppen, o clima do município de Três Corações é Cwb, ou seja, possui um clima mesotérmico, com temperatura média do mês mais quente inferior a $22{ }^{\circ} \mathrm{C}$. O aterro sanitário é caracterizado por três vegetações no entorno: mata nativa, área cultivada por batata e pastagem. $\mathrm{O}$ aterro de Três Corações possui área de 20,73 ha e solo classificado como Latossolo Vermelho-Amarelo.

O volume de resíduos sólidos coletados pela prefeitura no período estudado para o aterro sanitário é em média de 905 ton mês $^{-1}$ de resíduos sólidos domiciliares e 3,5 
ton mês $^{-1}$ de resíduos sólidos de serviço de saúde. A composição gravimétrica dos resíduos domiciliares destinados para o aterro sanitário do município de Três Corações é 53,5 \% Orgânico total; 29,7\% rejeitos; $16,5 \%$ de recicláveis e $0,3 \%$ resíduos perigosos.
Para a análise da água subterrânea foram analisados quatro poços de monitoramento distribuídos estrategicamente pela área (Tabela 1). $\mathrm{O}$ período de monitoramento teve início em janeiro de 2011 e ocorreu até o mês de novembro de 2011, com frequência quinzenal.

TABELA 1 - Descrição e localização dos poços de monitoramento.

\begin{tabular}{cccc}
\hline $\begin{array}{c}\text { Poços de } \\
\text { Monitoramento }\end{array}$ & Descrição & $\begin{array}{c}\text { Profundidade } \\
\text { (metros) }\end{array}$ & Coordenadas geográficas \\
\hline Poço 1 & Localizado a jusante da plataforma de RSU & 7,8 & $21^{\circ} 40^{\prime} 58^{\prime \prime} \mathrm{S}$ \\
$45^{\circ} 13^{\prime} 02^{\prime \prime} \mathrm{W}$ \\
Poço 2 & Localizado a jusante da plataforma de RSU & 9,4 & $21^{\circ} 40^{\prime} 56,6^{\prime \prime} \mathrm{S}$ \\
Poço 3 & Localizado a jusante da plataforma de RSU & 7,2 & $45^{\circ} 13^{\prime} 08^{\prime \prime} \mathrm{W}$ \\
& & & $21^{\circ} 40^{\prime} 56^{\prime \prime} \mathrm{S}$ \\
Poço 4 & Localizado a Montante da plataforma de RSU & 33,5 & $25^{\circ} 13^{\prime} 12^{\prime \prime} \mathrm{W}$ \\
\end{tabular}

Fonte: Os autores.

O nível de água nos poços de monitoramento foi feito com o auxílio de uma régua metro e observou-se a pouca variação dos níveis de água nos quatro poços de monitoramento. Os parâmetros $\mathrm{pH}$, condutividade elétrica, sólidos dissolvidos totais (SDT), sólidos totais fixos, sólidos totais voláteis, oxigênio dissolvido (OD), Demanda Bioquímica de Oxigênio (DBO), cloretos, alcalinidade, dureza, coliformes totais e termotolerantes, nitrato, nitrogênio amoniacal e fosfato foram analisados conforme descrito no Standard Methods for the Examination of Waterand Wastewater (APHA, 1998), sendo que para os parâmetros condutividade e $\mathrm{pH}$ foram utilizados respectivamente os aparelhos de marca PHTEK CD203 e HEXI SENSION 4.
O estudo baseou-se na análise da estatística descritiva, onde procurou descrever o comportamento dos diferentes parâmetros avaliados, estabelecendo comparações com os valores preconizados pela portaria n²914/2011 do Ministério da Saúde (MS) (BRASIL, 2011), a Resolução CONAMA n³96/2008 (BRASIL, 2008) e n420/2009 (BRASIL, 2009). Além da comparação dos pontos de amostragem a montante com os pontos a jusante, onde há possível influência da área de disposição dos RSU. Para avaliação das possíveis variações dos valores encontrados foi aplicado o teste estatístico " $\mathrm{t}$ " de student no nível de 5\% de significância, tendo sido comparados todos os parâmetros determinados em cada poço de 
monitoramento a jusante com os valores obtidos no poço a montante.

\section{RESULTADOS E DISCUSSÃO}

Na Tabela 2 são apresentados os resultados médios das variáveis físicas, químicas e bacteriológicas das 14 amostragens de água subterrânea para os 4 poços e os valores máximos permitido pela Portaria n²914/2011 do Ministério da Saúde.

TABELA 2 - Valores médios dos parâmetros analisados e os valores máximos permitidos (VPM) pela Portaria n²914/2011 do Ministério da Saúde.

\begin{tabular}{|c|c|c|c|c|c|}
\hline \multirow{2}{*}{ Parâmetro } & \multicolumn{4}{|c|}{ Poços } & \multirow{2}{*}{ VMP } \\
\hline & 1 & 2 & 3 & 4 & \\
\hline $\mathrm{pH}$ & 5,33 & 4,92 & 4,44 & 5,05 & 6 a 9,5 \\
\hline $\mathrm{DBO}_{5}\left(\mathrm{mg} \mathrm{L}^{-1}\right)$ & 4,26 & 15,13 & 76,07 & 2,34 & - \\
\hline Oxigênio Dissolvido (mg L $\mathrm{L}^{-1}$ ) & 8,65 & 7,27 & 7,19 & 8,89 & - \\
\hline Cloreto $\left(\mathrm{mg} \mathrm{L}^{-1}\right)$ & 15,5 & 18,29 & 16,71 & 14,93 & 250 \\
\hline Turbidez (UNT) & 12,78 & 198,77 & 441,81 & 15,93 & 5 \\
\hline Dureza $\left(\mathrm{mg} \mathrm{L}^{-1}\right)$ & 24,86 & 22,57 & 26,14 & 26 & 500 \\
\hline Alcalinidade $\left(\mathrm{mg} \mathrm{L}^{-1}\right)$ & 10,34 & 10,96 & 11,02 & 11,45 & - \\
\hline Condutividade $\left(\mu \mathrm{sm}^{-1}\right)$ & 9,19 & 49,2 & 12,36 & 26,99 & - \\
\hline Sólidos Totais (mg L $\left.{ }^{-1}\right)$ & 151,19 & 581,72 & 3021,67 & 91,43 & - \\
\hline Sólidos Fixos (mg L $\left.{ }^{-1}\right)$ & 97,46 & 447,97 & 1546,36 & 57,32 & - \\
\hline Sólidos Voláteis $\left(\mathrm{mg} \mathrm{L}^{-1}\right)$ & 53,87 & 133,75 & 1475,31 & 34,11 & - \\
\hline Sólidos Dissolvidos $\left(\mathrm{mg} \mathrm{L}^{-1}\right)$ & 5,88 & 31,49 & 7,91 & 17,27 & 1000 \\
\hline Coliformes Totais (NMP. $100 \mathrm{~mL}^{-1}$ ) * & $2,2 \times 10^{-3}$ & $5,0 \times 10^{-5}$ & $6,3 \times 10^{2}$ & $1,9 \times 10^{-3}$ & Ausente \\
\hline Coliformes Termotolerantes (NMP.100 $\mathrm{mL}^{-1}$ )* & $4,0 \times 10^{-6}$ & $3,0 \times 10^{-6}$ & $9,1 \times 10^{-3}$ & $5,0 \times 10^{-6}$ & Ausente \\
\hline Nitrogênio Amoniacal $\left(\mathrm{mg} \mathrm{L}^{-1}\right)$ & 9,52 & 9,68 & 8,36 & 9,16 & 1,5 \\
\hline Nitrato $\left(\mathrm{mg} \mathrm{L}^{-1}\right)$ & 2,11 & 1,66 & 2,04 & 1,2 & 10 \\
\hline Fósforo Total $\left(\mathrm{mg} \mathrm{L}^{-1}\right)$ & 0,88 & 1,13 & 0,74 & 0,81 & - \\
\hline
\end{tabular}

*Média geométrica.

Valores em negrito superam os VMP pela portaria n²914/2011 do MS.

Fonte: Os autores.

De acordo com a Portaria $n^{\circ}$ 2914/2011 do MS a faixa recomendada de $\mathrm{pH}$ na água distribuída é de 6,0 a 9,5. Todos os poços, inclusive o Poço 4 que serve como controle por estar situado a montante da plataforma de RSU, apresentaram $\mathrm{pH}$ médio abaixo de 6, o que indica a necessidade de um tratamento prévio da água do aqüífero para que esteja dentro do padrão de aceitação para consumo humano. Observa-se ainda um caráter ácido das mesmas. De acordo com Krieger (2000), este fato favorece a lixiviação de metais, concentrando-os dissolvidos na fase aquosa.

Em relação à $\mathrm{DBO}_{5}$ todos os poços indicaram a presença de carga orgânica, o que 
pode estar sendo influenciado a um funcionamento inadequado do aterro, que possui $53,5 \%$ de seus resíduos de orgânicos totais. Mas não se pode concluir que este indício de contaminação dos poços a jusante da plataforma sejam apenas da carga orgânica infiltrada devido ao chorume no aterro sanitário. Outra característica que reflete este indício é a turbidez, que apresentou elevados valores. $\mathrm{O}$ poço 3 mostrou-se com uma água barrenta em todo o período de amostragem. Os demais poços, a média e a máxima foram superiores ao permitido para a água potável (5UNT), mas com valores inferiores ao poço 3.

Os valores de sólidos totais apresentaram ampla variação sazonal, sendo o poço 3 com elevada concentração de carga sólida, tanto os sólidos fixos, relativos ao material inerte, e os sólidos voláteis, referentes aos materiais orgânicos. O que pode ser resultado da proximidade do poço com o mau funcionamento de um sistema de drenagem que pode estar provocando a sedimentação do material. As concentrações de OD apresentaram-se com valores elevados, sendo que alguns se encontraram na faixa típica de águas subterrâneas, entre 0 e $5 \mathrm{mgL}^{-1}$, conforme citam Feitosa et al., (2008).

A maioria das amostras de água proveniente dos poços teve contagens elevadas do grupo coliforme totais, principalmente no período chuvoso onde houve um aumento significativo, com grande variação ao longo de todo o monitoramento.
Resultado semelhante foi obtido em estudo realizado no aterro sanitário de Cuiabá, onde também se observou grande variação dos coliformes totais (SANTOS, 2008). Elevada concentração de coliformes termotolerantes também se mostrou presente em algumas amostragens. A presença dos coliformes termotolerantes e totais podem ter associação com de materiais orgânicos oriundos de banheiro, como papéis higiênicos usados e fraldas descartáveis depositados no aterro. Fato este que pode ser explicado pelo transporte de bactérias no solo até ao lençol freático. Alguns estudos realizados mostraram que as distâncias percorridas por esses organismos podem chegar a quilômetros. Entretanto, Coelho (2007) salienta que é difícil fazer generalizações a respeito da distância percorrida por microorganismos no solo, uma vez que o movimento está relacionado diretamente com os valores de carga hidráulica.

Os níveis de cloretos, em todas as amostras coletadas foram abaixo do valor de referência permitido para o consumo humano (250 mg L $\left.\mathrm{L}^{-1}\right)$. A condutividade não se apresentou com resultados elevados em nenhum dos poços monitorados, variando entre 3,2 e $79,5 \mu \mathrm{s} \mathrm{cm}^{-1}$. Não há padrão de potabilidade estabelecido pelo MS, entretanto segundo a CETESB (2005) valores acima de $100 \mu \mathrm{s} \mathrm{cm}^{-1}$ representam ambientes impactados. Observou-se que os maiores valores de condutividade ocorreram no Poço 2, assim como as altas concentrações de 
cloreto, demonstrando a presença de sais na água.

Em relação aos SDT, nenhum dos poços superou o valor máximo permitido de $1000 \mathrm{mg} \mathrm{L}^{-1}$ pelo MS e pela Resolução $\mathrm{n}^{\circ}$ $396 / 2008$ para se ter como uso o consumo humano. O parâmetro dureza, em todos os pontos amostrados, encontrou-se abaixo do padrão estabelecido pela Portaria $\mathrm{n}^{\circ} 2914 / 2011$ do $\mathrm{MS}$ (500 $\left.\mathrm{mg}^{-1}\right)$. A alcalinidade também apresentou pouca variação entre os pontos amostrados, de 5 a $23 \mathrm{mg} \mathrm{L}^{-1}$.

A presença de nitrato aparentemente não foi alta levando em consideração a
Portaria $n^{\circ} 2914 / 2011$ do MS e a Resolução $\mathrm{n}^{\circ} 420 / 2009$ (10 $\left.\mathrm{mg} \mathrm{L}^{-1}\right)$. Salienta-se que o nitrato é a forma mais oxidada de nitrogênio, indicando poluições não tão recentes. Em relação ao nitrogênio amoniacal, em todas as amostras das campanhas realizadas, foram detectadas teores elevados, acima de 1,5 mg $\mathrm{L}^{-1}$. O nitrogênio, na forma amoniacal, indica a ocorrência de contaminação direta por matéria orgânica. A figura 1 traz $o$ comportamento dessa variável nitrogênio amoniacal ao longo dos 4 poços de coleta.

FIGURA 1 - Variação da concentração de nitrogênio amoniacal $\left(\mathrm{mg} \mathrm{L}^{-1}\right)$.

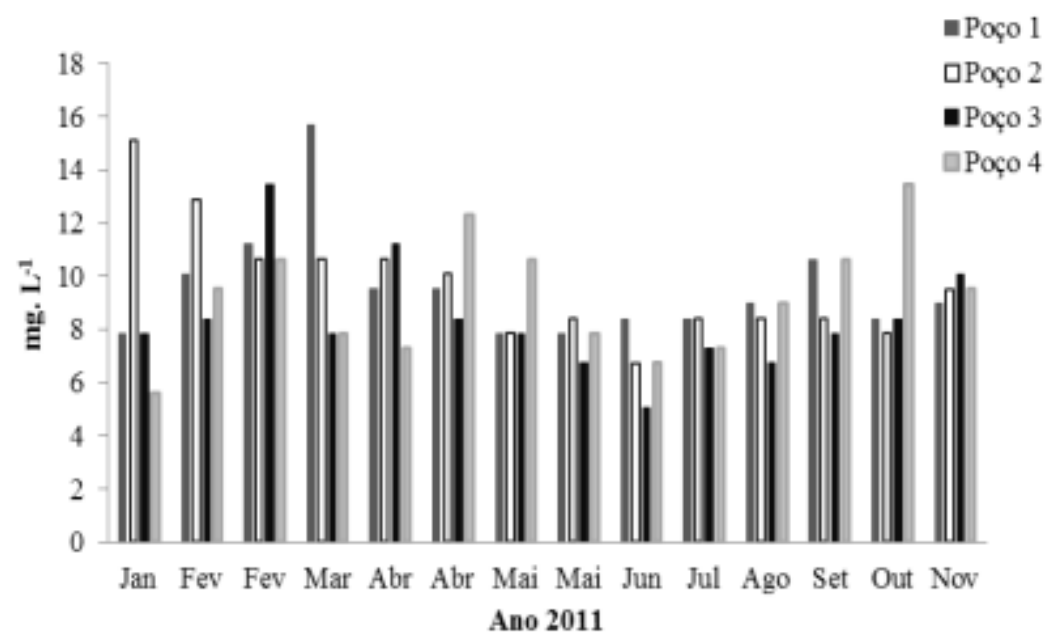

Fonte: Os autores.

A concentração de fósforo nos poços 1, 3 e 4 apresentaram variações idênticas, entre 0,4 a $1,2 \mathrm{mg} \mathrm{L}^{-1}$ e o poço 2 apresentou uma variação entre 0,5 e $1,2 \mathrm{mg} \mathrm{L}^{-1}$ (Figura 2). O fósforo devido a ações antrópicas pode ser acrescido ás águas subterrâneas por derivados de fertilizantes, efluentes domésticos, detergentes, pesticidas e inseticidas e teores acima de $1,0 \mathrm{mg} \mathrm{L}^{-1}$ normalmente são indicativos de contaminação (Feitosa, 2008). 
FIGURA 2 - Concentração fósforo total $\left(\mathrm{mg} \mathrm{L}^{-1}\right)$ nos poços de monitoramento

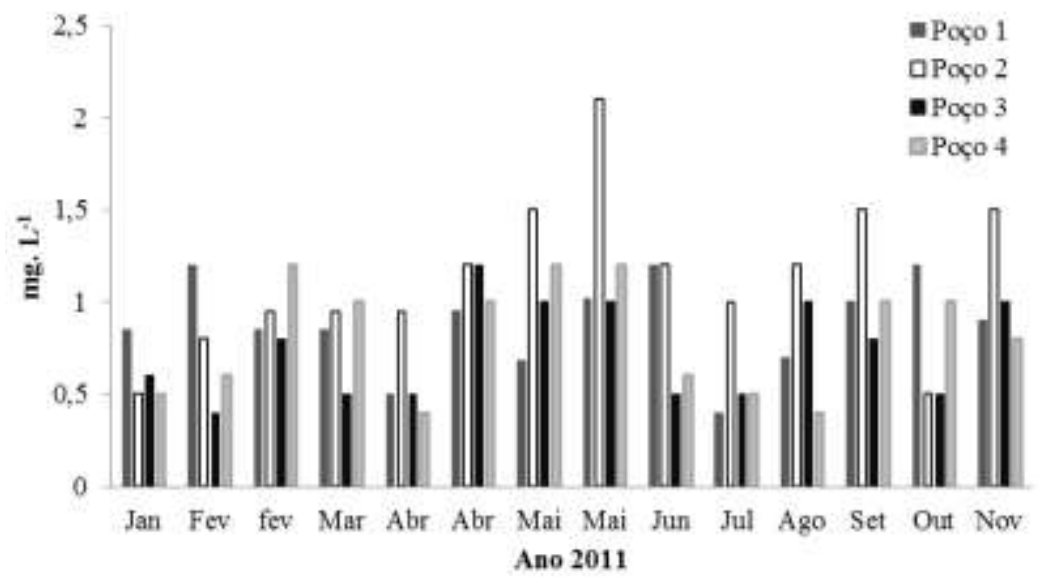

Fonte: Os autores.

\subsection{Estatística "t" de Student}

O poço 4 serviu como controle por estar situado a montante da área da plataforma encerrada e de operação dos RSU, em um ponto alto topográfico, praticamente sem influência da poluição provocada pelo depósito dos RSU. Seguem na Tabela 3 os resultados do teste " $\mathrm{t}$ " estatístico de Student no nível de 5\% de significância. Os valores em negrito significam que houve uma diferença significativa do parâmetro no poço comparado com o a montante.

TABELA 3 - Resultados do Teste estatístico "t" de student no nível de 5\% de significância para os poços a jusante amostrados em comparação ao poço 4 a montante.

\begin{tabular}{llll}
\hline Parâmetros & Poço 4 e 1 & Poço 4 e 2 & Poço 4 e 3 \\
\hline pH & 0,400 & 0,208 & $\mathbf{0 , 0 0 0}$ \\
Oxigênio Dissolvido & 0,709 & $\mathbf{0 , 0 0 5}$ & $\mathbf{0 , 0 2 1}$ \\
Condutividade & $\mathbf{0 , 0 0 0}$ & $\mathbf{0 , 0 0 0}$ & $\mathbf{0 , 0 0 0}$ \\
Turbidez & 0,526 & $\mathbf{0 , 0 4 2}$ & $\mathbf{0 , 0 0 0}$ \\
Cloreto & 0,668 & $\mathbf{0 , 0 2 2}$ & $\mathbf{0 , 0 1 7}$ \\
Alcalinidade & 0,348 & 0,709 & 0,745 \\
Dureza & 0,704 & 0,340 & 0,963 \\
DBO & 0,234 & $\mathbf{0 , 0 2 2}$ & $\mathbf{0 , 0 0 6}$ \\
Nitrogênio Amoniacal & 0,678 & 0,597 & 0,342 \\
Nitrato & $\mathbf{0 , 0 1 0}$ & 0,083 & $\mathbf{0 , 0 0 9}$ \\
Fósforo Total & 0,550 & $\mathbf{0 , 0 1 2}$ & 0,423 \\
\hline
\end{tabular}

*Valores em negrito significam que houve diferença entre os resultados.

Fonte: Os autores.

Pode-se observar que o poço 1 quase não apresentou diferença nos resultados dos parâmetros analisados com o poço a montante, apenas a condutividade e o nitrato.
Este poço não está sofrendo tanta influência de lixiviação do chorume em comparação aos demais poços. Em relação aos poços 2 e 3 nota-se que vários parâmetros apresentaram 
variação significativa dos resultados em relação ao poço a montante 4 . Estes poços podem estar sofrendo uma maior influência do aterro sanitário devido a seus posicionamentos a jusante da plataforma de RSU.

\section{CONCLUSÕES}

A água subterrânea dos poços apresentou concentrações alteradas de turbidez, Coliformes, nitrogênio e teores elevados de $\mathrm{DBO}_{5}$, o que demonstra indicações de contaminação por matéria orgânica. Há, portanto, fortes indícios de que o aterro sanitário de Três Corações está impactando negativamente a qualidade da água sob a sua influência. Destaca-se também que, principalmente os poços 2 e 3 apresentaram vários indicadores com valores significativamente diferentes comparado com o poço a montante, o que pode estar associado a posição dos mesmos. Entretanto, salienta-se que a partir da análise deste estudo não se pode afirmar que a contaminação tenha origem apenas da migração do lixiviado do aterro, mas também, de fontes externas como as práticas agrícolas no entorno, uma vez que os pontos a montante da plataforma do aterro também apresentaram violações dos níveis admissíveis pela legislação. A identificação e avaliação destas alterações nas amostras de água subterrânea servem de subsídio para o desenvolvimento de programas de monitoramento da qualidade da água em áreas de disposição de resíduos sólidos.

\section{REFERÊNCIAS}

APHA (AMERICAN PUBLIC HEALTH ASSOCIATION). Standard methods for the examination of water and wastewater. $20^{\text {th }}$ ed. Washington, D.C.: APHA/AWWA/WPCP, 1998. 1325p.

BRASIL. Ministério da Saúde. Portaria $\mathrm{n}^{\circ}$ 2.914, de 12 de dezembro de 2011. Dispõe sobre os procedimentos de controle e vigilância da qualidade da água para consumo humano e seu padrão de potabilidade. Diário Oficial [da] União, Brasília, DF, 2011. Disponível em: <http://bvsms.saude.gov.br/bvs/saudelegis/gm /2011/prt2914_12_12_2011.html >. Acesso em: 18 maio 2016.

BRASIL. Ministério do Meio Ambiente. Conselho Nacional de Meio Ambiente. Resolução n 396, de 03 de abril de 2008. Dispõe sobre a classificação e diretrizes ambientais para o enquadramento das águas subterrâneas e dá outras providências. Diário Oficial [da] União, Brasília, DF, 2008. Disponível em: <http://www.mma.gov.br/port/conama/legiabr e.cfm?codlegi=562>. Acesso em: 18 maio 2016.

BRASIL. Ministério do Meio Ambiente. Conselho Nacional de Meio Ambiente. Resolução ${ }^{\circ} 420$, de 28 de dezembro de 2009. Dispõe sobre critérios e valores orientadores de qualidade do solo quanto à presença de substâncias químicas e estabelece diretrizes para o gerenciamento ambiental de áreas contaminadas por essas substâncias em decorrência de atividades antrópicas. Diário Oficial [da] União, Brasília, DF, 2009.

Disponível em: <http://www.mma.gov.br/port/conama/legiabr e.cfm?codlegi $=620>$. Acesso em: 18 maio 2016. 
COELHO, V. M. T. Potencial de contaminação de aqüífero por esgoto doméstico: quantificação do decaimento bacteriológico. 2007. 129 p. Tese (Doutorado em Recursos Minerais e Hidrogeologia) Universidade de São Paulo, São Paulo, 2007.

CETESB (COMPANHIA DE

TECNOLOGIA DE SANEAMENTO

AMBIENTAL) (2005) Decisão de diretoria $\mathrm{n}^{\circ}$ 195-2005-E, de 23 de novembro de 2005.

Dispõe sobre a aprovação dos valores orientadores para solos e águas subterrâneas no estado de São Paulo - 2005, em substituição aos valores orientadores de 2001, e dá outras providências. Diário Oficial [do]

Estado de São Paulo, Poder Executivo, São Paulo, SP, 2005a. Seção 1, v. 115, n. 227, p. 22-23. Disponível em:

$<$ http://solo.cetesb.sp.gov.br/wpcontent/uploads/sites/34/2014/12/tabela_valor es_2005.pdf >. Acesso em: 11 janeiro 2016.

COTRIM, M. E. B. Avaliação da qualidade da água na bacia hidrográfica do ribeirão de Iguape com vistas ao abastecimento público. 2006, 236 p. Tese (Doutorado em Tecnologia Nuclear - Materiais) Universidade de São Paulo, São Paulo, 2006.

FEITOSA, F. A. C. et al. Hidrogeologia, conceitos e aplicações. $3^{\mathrm{a}}$ ed. Rio de Janeiro, CPRM/LABHID, 2008812 p.

IBGE (INSTITUTO BRASILEIRO DE GEOGRAFIA E ESTATÍSTICA) Pesquisa nacional de saneamento básico. 2008.
Disponível em:

<http://biblioteca.ibge.gov.br/visualizacao/liv ros/liv45351.pdf >. Acesso em: 11 janeiro 2016.

IBGE (INSTITUTO BRASILEIRO DE GEOGRAFIA E ESTATÍSTICA) Censo Demográfico 2010. 2010. Disponível em: < http://cidades.ibge.gov.br/xtras/perfil.php?lan $\mathrm{g}=\&$ codmun $=316930>$. Acesso em: 11 janeiro 2016.

KRIEGER, E. I. F. Avaliação da contaminação da água subterrânea na área de influência da Usina de Tratamento de Resíduos S/A - UTRESA, em Estância Velha (RS). 2000. 158p. Dissertação (Mestrado em Ecologia). Universidade do Rio Grande do Sul, Porto Alegre.2000.

SANTOS, A. A. Qualidade das águas superficiais e subterrâneas na área de influência do aterro sanitário de Cuiabá MT. 2008. 111 p. Dissertação (Mestrado em Física Ambiental) - Universidade Federal do Mato Grosso, Cuiabá. 2008.

TUCCI, C. E. M; MENDES, C. A. Avaliação ambiental integrada de bacia hidrográfica. Brasília: Ministério do Meio Ambiente, 2006 302p. 